\title{
PELATIHAN PEMBUATAN DIGESTER BIOGAS SEDERHANA BAGI KELOMPOK PKK NEFONAEK
}

\author{
Rima N. Selan ${ }^{1)}$, Adi Y. Tobe ${ }^{1)}$, Yeremias M. Pell ${ }^{1)}$ \\ ${ }^{1)}$ Program Studi Teknik Mesin, Fakultas Sains dan Teknik, Universitas Nusa Cendana Kupang \\ Corresponding author : Rima N. Selan \\ E-mail :rima_selan@staf.undana.ac.id
}

Diterima 12 November 2020, Direvisi 15 November 2020, Disetujui 15 November 2020

\begin{abstract}
ABSTRAK
Kelurahan Nefonaek merupakan salah satu kelurahan di Kota Kupang yang padat penduduknya,hal ini sudah tentu berpengaruh besar pada sampah yang dihasilkan. Karena banyaknya sampah yang dihasilkan, maka seringkali masyarakat membuang tidak pada tempatnya. Seperti yang terjadi di Jalan Supul 2, sampah - sampah dibuang oleh masyarakat di tanah kosong depan perumahan. Tujuan dari kegiatan ini adalah untuk memberikan pengetahuan tentang pengelolaan sampah rumah tangga dan praktek pembuatan digester biogas sederhana. Melalui kegiatan ini diharapkan ibu - iubu rumah tangga dapat mengolah sampah rumah tangga menggunakan digester biogas sederhana. Metode yang digunakan dalam pengabdian adalah metode ceramah, tanya jawab, diskusi, simulasi dan praktik. Hasil dari kegiatan pengabdian ini yaitu ibu - ibu kelompok PKK Nefonaek mendapat pengetahuan tentang cara mengelola sampah organik, serta dapat membuat digester biogas sederhana dengan menggunakan bahan yang ada disekitar perumahan.
\end{abstract}

Kata kunci: sampah organik; pengelolaan sampah; digester biogas sederhana.

\begin{abstract}
Kelurahan Nefonaek is one of the urban villages in Kupang City which is densely populated, this of course has a big effect on the waste produced. Because of the large amount of waste generated, people often dispose of it inappropriately. As happened on Jalan Supul 2, the community discards garbage on the empty land in front of the housing. The purpose of this activity is to provide knowledge about household waste management and the practice of making a simple biogas digester. Through this activity, it is hoped that housewives can process household waste using a simple biogas digester. The methods used in the community service are lecture, question and answer, discussion, simulation, and practice methods. The results of this service were that the women of the Nefonaek PKK group got knowledge about how to manage organic waste, and were able to make a simple biogas digester using materials around the housing.
\end{abstract}

Keywords: organic waste; waste management; a simple biogas digester.

\section{PENDAHULUAN}

Kebutuhan energi terus meningkat seiring dengan pertumbuhan penduduk dan peningkatan taraf ekonomi masyarakat. Berdasarkan infor- masi yang ada menyatakan bahwa persediaan bahan bakar fosil atau BBM (bahan bakar mi- nyak) di Indonesia pada umumnya semakin menipis. Biogas merupakan salah satu hasil dari pemanfaatan limbah kotoran ternak. Biogas ter- bentuk oleh proses fermentasi secara anaero- bik oleh bakteri methan dan bakteri biogas. Gas yang dihasilkan berupa jenis metana $(\mathrm{CH} 4)$ yang bersifat mudah terbakar (Ilham Salim1 dan Frans Kafiar, 2017).

Sampah masih menjadi persoalan utama di Kota Kupang, sumber sampah terbesar adalah dari permukiman warga. Sampah yang dibhasilkan oleh rumah tangga terbagi menjadi sampah organik dan anorganik. Kurangnya pengetahuan dalam pengelolaan sampah mengakibatkan masyarakat membuang semua jenis sampah ke lingkungan, padahal dengan pengelolaan yang baik dan benar sampah bisa dijadikan barang yang berguna dan mempunyai nilai tambah.

Kelurahan Nefonaek merupakan salah satu kelurahan di Kota Kupang yang padat penduduknya, hal ini sudah tentu berpengaruh besar pada sampah yang dihasilkan seperti dititunjukkan pada Gambar 1. Sampah rumah tangga yang dihasilkan (baik organik maupun anorganik) dibuang oleh masyarakat di tanah kosong depan perumahan karena bak sampah yang selama ini digunakan sudah rusak dan belum ada bak sampah yang baru sebagai 
tempat penampungan sampah sementara sebelum diangkut ke TPA.

Berkaitan dengan kondisi iklim, sampah berpotensi memberi sumbangan terhadap meningkatnya emisi gas rumah kaca, akibat penumpukan sampah tanpa diolah dapat melepaskan gas metana $\left(\mathrm{CH}_{4}\right)$. Seringkali masyarakat juga membakar sampah -sampah yang belum diangkut petugas kebersihan, sudah tentu hal ini sangatlah berdampak negatif bagi warga yang tinggal dekat dengan tempat pembuangan sampah, bisa dilihat pada Gambar 2.

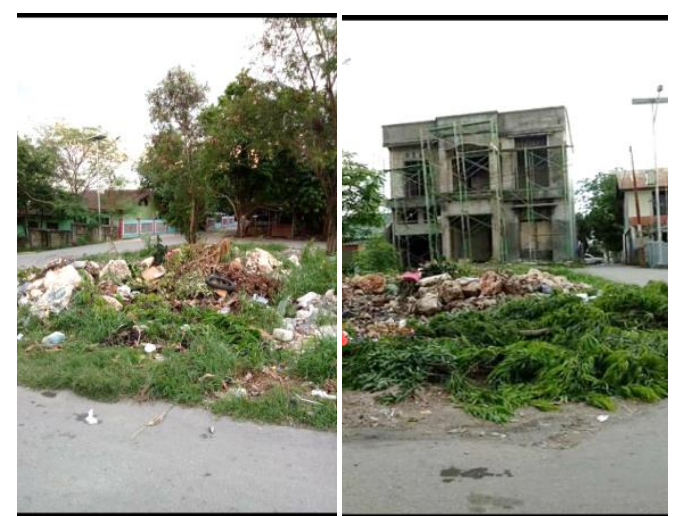

Gambar 1. Timbunan sampah di tanah lapang dekat kawasan perumahan

Kondisi ini sangat memprihatinkan karena selain merusak pemandangan, kebiasaan buang sampah sembarangan dapat menimbulkan kemunculan penyakit. Jika kebiasaan ini dilakukan dalam jangka panjang, dampak buruknya akan lebih luas lagi, yaitu dapat menurunkan kualitas hidup manusia.

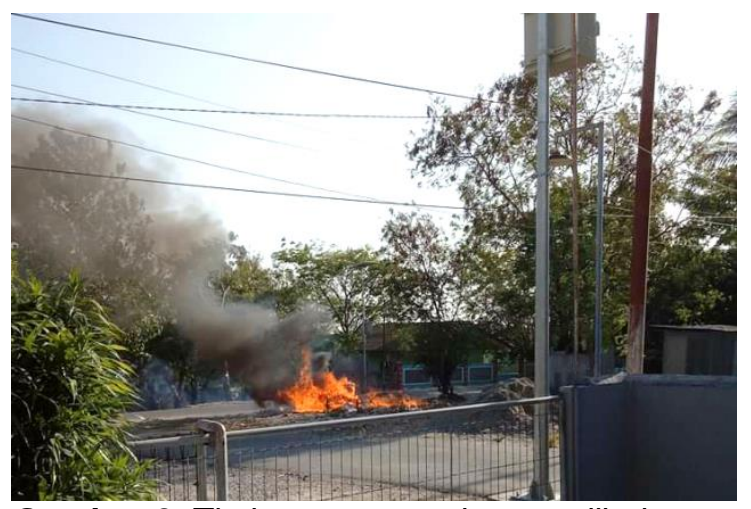

Gambar 2. Timbunan sampah yang dibakar

Masyarakat dihimbau untuk mengumpulkan dan mendaur ulang sampah anorganik menjadi barang yang memiliki nilai jual, sedangkan untuk sampah organik dapat diatasi dengan inovasi biogas sebagai alternatif sumber energi bagi masyarakat. Selain itu melakukan pengelolaan sampah dapat memberi manfaat antara lain sumber pendapatan bagi masyarakat karena menghemat biaya bahan bakar minyak tanah, penghematan sumber daya alam, penghematan energi, penghematan lahan TPA dan lingkungan yang bersih, sehat serta nyaman. Sebagian besar masyarakat di Kota Kupang masih menggunakan minyak tanah untuk bahan bakar, melihat kelangkaan dan mahalnya harga minyak tanah di pasaran maka inovasi biogas merupakan alternatif terbaik yang dapat diaplikasikan di masyarakat Kota Kupang.

Dari analisa situasi diatas, diketahui bahwa permasalahan yang dihadapi kelompok PKK Kelurahan Nefonaek adalah :

- Belum adanya informasi teknologi pengelolaan sampah baik organik maupun anorganik

- Belum berkembangnya jiwa peduli sampah pada kelompok mitra. Sehingga melalui kegiatan ini perlu dilakukan pelatihan dan pendampingan kepada mitra agar dapat mengelola sampah dengan lebih teratur.

Tujuan dari kegiatan ini adalah untuk memberikan pengetahuan tentang pengelolaan sampah rumah tangga dan praktek pembuatan digester biogas sederhana. Melalui kegiatan ini diharapkan ibu - iubu rumah tangga dapat mengolah sampah rumah tangga menggunakan digester biogas sederhana.

\section{METODE}

Kegiatan pengabdian kepada masyarakat yang dilakukan adalah memntransfer ilmu dan pengetahuan tentang pengelolaan sampah menjadi biogas dilakukan oleh dosen dan mahasiswa jurusan Teknik Mesin FST Undana dengan menampilkan digester biogas yang dirancang sendiri. Digester yang digunakan menggunakan ember besar dan galon. Hal ini dimaksudkan agar ibu - ibu PKK tidak merasa kesusahan karena bahan - bahan tersebut mudah didapat.

Kegiatan dilakukan di Aula Kantor Kelurahan Nefonaek dan diikuti oleh 125 orang ibu - ibu pengurus dasawisma Kelurahan Nefonaek dan mahasiswa - mahasiswa Jurusan Teknik Mesin Undanadiperuntukkan bagi Kelompok PKK Nefonaek yang sebagian besar adalah ibu rumah tangga. Metode yang digunakan dalam pengabdian adalah metode ceramah, tanya jawab, diskusi, simulasi dan praktik.

Tahapan - tahapan yang ditempuh guna melaksanakan solusi atas permasalahan mitra, antara lain :

1. Menggali dan mengkaji permasalahan yang dihadapi mitra melalui wawancara/dialog yang mendalam tentang proses pengelolaan sampah Kelurahan Nefonaek. 
2. Menetapkan solusi yang sesuai dengan persoalan yang dihadapi mitra dan mengumpulkan data - data awal sebagai landasan dalam menawarkan solusi kepada mitra.

3. Menawarkan solusi kepada mitra berupa kegiatan pengelolaan sampah yang lebih baik, sehingga mitra juga memperoleh masukan dalam bidang ilmu pengetahuan dan teknologi.

4. Melakukan kesepakatan bersama dalam hal teknis penyelesaian persoalan mitra.

5. Penyediaan alat dan bahan untuk meningkatkan proses pembuatan digester biogas.

6. Melakukan pendampingan dan pengawasan setelah program selesai sampai mitra mandiri dalam memanfaatkan teknologi ini secara penuh.

Gas yang dihasilkan akan tertampung pada bagian atas digester. Terjadinya penumpukan produksi gas akan menimbulkan tekanan sehingga dari tekanan tersebut gas dapat disalurkan melalui pipa yang dipergunakan untuk keperluan bahan bakar atau pembangkit listrik. Gas tersebut sangat baik untuk pembakaran karena menghasilkan panas yang tinggi, tidak berbau, tidak berasap, dan api yang dihasilkan berwarna biru. Selain itu, pupuk kandang yang dihasilkan dari pembuangan bahan biogas ini akan menaikkan kandungan bahan organik sehingga menjadi pupuk kandang yang sangat baik dan siap pakai. Kesetaraan biogas dengan sumber energi lain, yaitu $1 \mathrm{~m} 3$ biogas setara dengan : elpiji $0,46 \mathrm{~kg}$, minyak tanah 0,62 liter, minyak solar 0,52 liter, bensin 0,80 liter, gas kota 1,50 m3, dan kayu bakar $3,50 \mathrm{~kg}$ (Andhini, 2017).

Untuk pembuatan digester biogas perangkat utama yang digunakan adalah tabung digester sebagai tempat penampung limbah biogas, pipa penyambung, katup, dan alat untuk identifikasi gas. Cara kerja sistem biogas adalah dengan memasukan bahan organik ke dalam tabung digester yang berfungsi sebagai perombak (digester) sehingga bakteri anaerob akan membusukkan bahan organik didalamnya dan dapat menghasilkan gas. Biogas dari digester kemudian dialirkan melalui pipa penyalur/penyambung menuju tabung penyimpan gas, atau bisa langsung ke tempat penggunaannya seperti ke tungku.

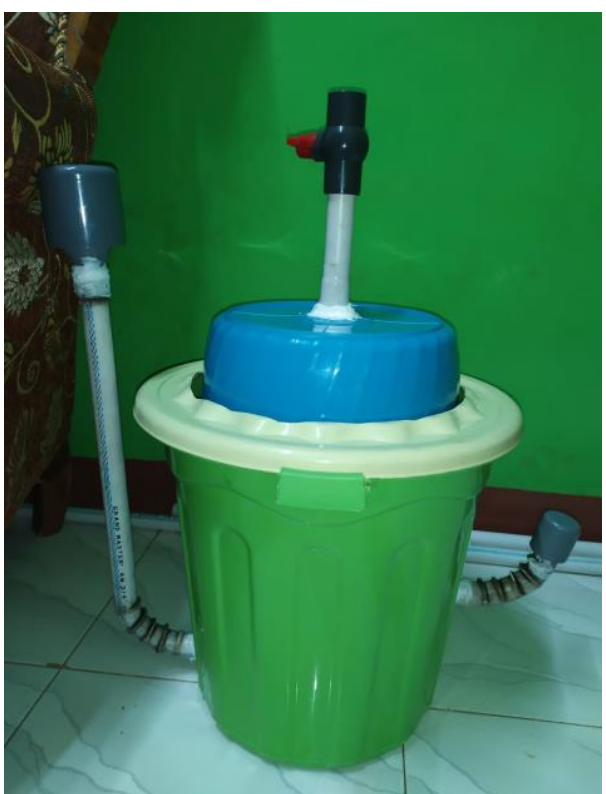

Gambar 3. Digester Bigas dari Ember

\section{HASIL DAN PEMBAHASAN \\ Pelaksanaan dan Metode Pembuatan Digester Biogas Sederhana}

Untuk pembuatan digester biogas sederhana, langkah -langkahnya sebagai berikut :

1. Penutup drum digester dibuat lubang pada permukaannya dengan ukuran 4 inchi yang nantinya kan berfungsi sebagai lubang pemasukan kotoran. Setelah itu dibuat lagi lubang pada permukaan tutup drum sebesar 1 inchi yang akan berfungsi sebagai saluran biogas menuju kompor atau penampung. Pada sisi sampingdrum dibuatkan lubang dengan ukuran $3 / 4$ inchi yang berjarak $20 \mathrm{~cm}$ dari permukaan yang akan berfungsi sebagai lubang pembuangan slurry biogas.

2. Pipa paralon ukuran 4 inch, $3 / 4$ inch dan 1 inch dipotong sesuai ukuran kebutuhan dan ukuran yangtelah dibuat dibuat.

3. Semua komponen dirakit menjadi satu. Pertama pipa 4 inchi dimasukkan dari atas lalu direkatkan dengan lem. Demikian pula kran 1 inchi sebagai saluran gas dan kran $3 / 4$ inchi sebagai pembuangan slurry.

4. Bahan input biogas (berupa limbah organik/ kotoran ternak segar) dicampur dengan air, dengan perbandingan $1: 1$

5. Campuran tersebut diaduk, kemudian dialirkan kedalam reaktor biogas sampai batas optimal lubang pengeluaran.

6. Didiamkan selama $2-3$ minggu, dengan posisi kran gas kontrol dan kran pengeluaran ke kompor dalam keadaan tertutup. 
7. Hasil proses fermentasi terlihat pada akhir minggu ke 2, karena sifatnya ringan maka biogas akan terkumpul di bagian atas kubah reaktor.

8. Gas pertama yang terbentuk dikeluarkan sampai keluar bau khas biogas.

9. Apabila pemakaian biogas setiap hari, maka pengisian bahan input biogas setiap hari.

10. Produksi biogas akan berlangsung secara terus menerus, tergantung pengisian dan pemeliharaan instalasi.

11. Menghindari masuknya pestisida, desinfektan, larutan deterjen/ sabun/ shampo ke dalam reaktor biogas.

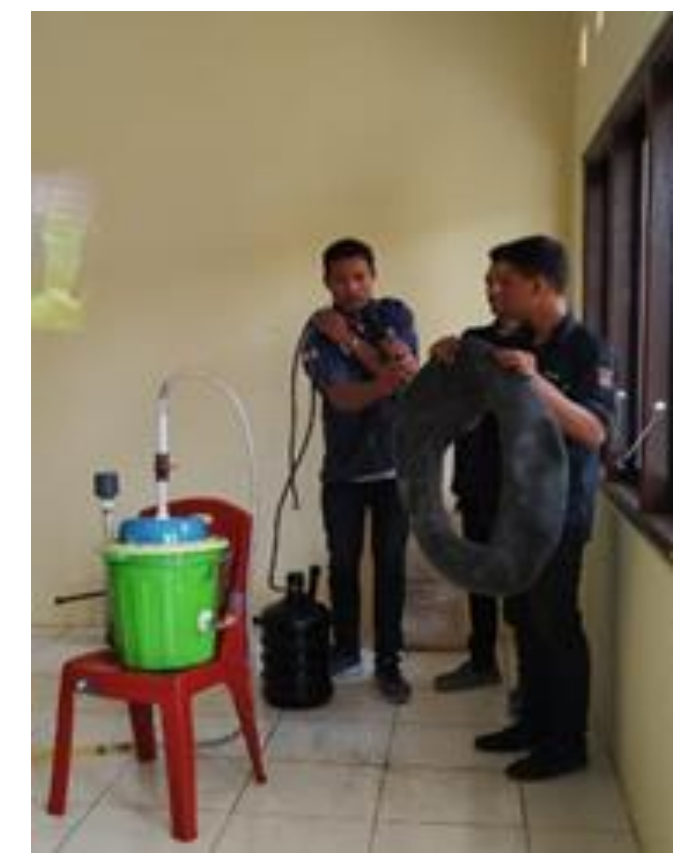

Gambar 4.Penjelasan tentang Pembuatan Digester Biogas

Proses pembuatan biogas dengan menggunakan biodigester pada prinsipnya adalah menciptakan suatu sistem kedap udara dengan bagian-bagian pokok yang terdiri dari tangki pen- cerna (digester tank), lubang input bahan baku, lubang output lumpur sisa hasil pencernaan (slurry) dan lubang penyaluran biogas yang ter- bentuk. Dalam digester terkandung bakteri meta- na (Methanobacterium omelianski) yang akan mengolah limbah organik menjadi biogas. Bakteri pembentuk biogas yang digunakan yaitu bakteri anaerob seperti Methanobacterium, Methano- bacillus, Methanococcus dan Methanosarcina(Basri et al., 2019).

Pemanfaatan biogas skala rumah tangga biasanya untuk bahan bakar dan penerangan. Sebagai sumber energi alternatif maka kandungan 1 m3biogassetara dengan: 0,46 kg elpiji, 0,62 It minyak tanah, 0,52 It minyak solar, 0,80 It bensin, 3,5 kg kayu bakar(Daroini. A., 2015).

Dalam pembuatan biogas, diperlukan suatu rangkaian alat yang disebut digester atau reaktor biogas. Selama ini di Indonesia dikenal dua jenis model digester, yaitu model India (Floating Cover) dan model China (Fixed Done) (Depdagri, 2008: 1-2). Masing- masing model digester mempunyai kelebihan dan kekurangan. Pada model India, tutup atas terbuat dari plat besi sehingga mudah dibuka untuk membersihkan kotoran/kerak di dalam reaktor. Namun kelemahan dari model ini adalah biaya lebih mahal karena tutup mudah berkarat sehingga harus sering diganti. Pada model China, reaktor dan kubah seluruhnya dibuat dari batu bata dan ditanam di tanah. Keuntungan dari model ini adalah biaya lebih murah, namun kelemahannya sulit untuk membersihkan kotoran/kerak (Sunyoto, Danang Dwi Saputro, 2016).

\section{Keunggulan Reaktor Biogas}

Berikut ini adalah beberapa keunggulan reaktor biogas skala rumah tangga :

- Konstruksi sederhana, mudah dan cepat pemasangannya (tidak sampai 1 hari).

- Harga terjangkau, sekitar Rp 2,5 juta sudah termasuk pemasangan dan satu unit kompor biogas.

- Awet, menggunakan material plastik khusus sehingga tahan hingga 6 tahun.

- Mudah dalam perawatan dan penggunaan. ? Produksi gas setara dengan 2,5 liter minyak tanah/hari, lebih dari cukup untuk dijadikan bahan bakar memasak.

- Menghasilkan kompos (pupuk organik) yang sangat bagus kualitasnya dan dapat langsung digunakan pada lahan/usaha budidaya pertanian(Sugandi, Dede; Eridiana, Wahyu; Malik, Yakub; T. Sugito, 2009).

\section{Pelatihan dan Tanggapan Peserta}

Berdasarkan hasil observasi yangdilakukansebelum pelaksanaan kegiatan,terdapat masalah terkait pengolahan sampah yaitu pemahaman pemanfaatan sampah organik menjadi biogas dan pembuatan digester biogas sederhana untuk skala rumah tangga.

Penyuluhan pengelolaan sampah menjadi biogas dilakukan oleh dosen dan mahasiswa jurusan Teknik Mesin FST Undana dengan menampilkan digester biogas yang dirancang sendiri. Digester yang digunakan antara lain jerigen, galon dan ember besar. Hal ini dimaksudkan agar ibu - ibu PKK tidak 
merasa kesusahan karena bahan - bahan tersebut mudah didapat.

Kegiatan dilakukan di Aula Kantor Kelurahan Nefonaek dan diikuti oleh 125 orang ibu - ibu pengurus dasawisma Kelurahan Nefonaek dan mahasiswa - mahasiswa Jurusan Teknik Mesin Undana.

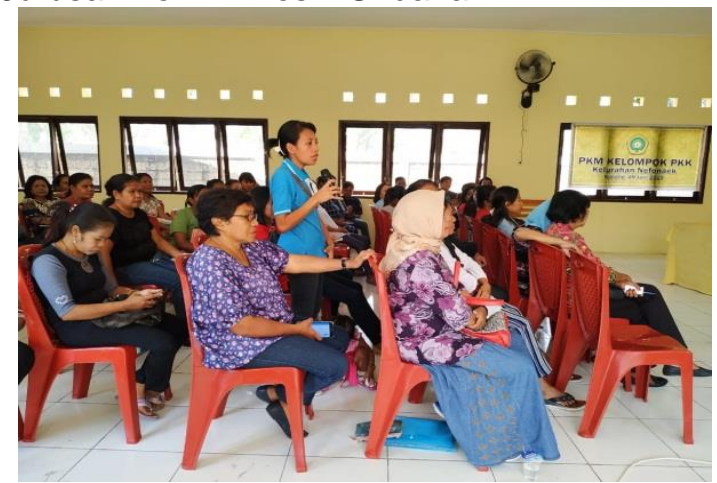

Gambar 5.Kelompok PKK Kelurahan Nefonaek antusias dalam mengikuti penyuluhan

\section{SIMPULAN DAN SARAN}

Beberapa hal yang dapat disimpulkan dari kegiatan IbM antara lain : 1) Proses pembuatan digester biogas sangatlah mudah dan dapat dipahami dengan baik oleh ibu - ibu kelompok PKK Kelurahan Nefonaek. 2) Pada awal pengisian digester diisi dengan air + kotoran hewan dan diulang pada hari ketiga. Hari - hari selanjutnya digester bisa diisi dengan air cucian beras, makanan sisa, sayuran sisa atau kulit pisang yang dipotong kecil - kecil.

\section{UCAPAN TERIMAKASIH}

Kami mengucapkan limpah terima kasihkepada LP2M Universitas Nusa Cendana Kupang yang telah mendanai kegiatanpengabdian kepada masyarakat (PKM) Dosen.

\section{DAFTAR RUJUKAN}

Andhini, N. F. (2017). Biogas Energi Ramah Lingkungan. Journal of Chemical Information and Modeling, 53(9), 16891699.

Basri, A. K., Kadirman, \& P, J. (2019). Rancang Bangun Reaktor Biogas Skala Rumah Tangga Design the Biogas Reactor Household Scale. Jurnal Pendidikan Teknologi Pertanian, 5(1), 79-84.

Daroini. A., E. R. \& E. S. (2015). TEKNOLOGI BIOGAS SKALA RUMAH TANGGA DI KELOMPOK TANI TERNAK GANGSAR MAKMUR KECAMATAN PUNCU KABUPATEN KEDIRI. Versi Online/ URL :

Http://Ejournal.Umm.Ac.Id/Index.Php/Ded ikasi/Article/View/, 0354, 683756.
Ilham Salim1 dan Frans Kafiar. (2017). PEMBUATAN ALAT PENGHASIL BIOGAS SEDERHANA DI KAMPUNG HAWAI KABUPATEN JAYAPURA. Jurnal Pengabdian Papua, 1(2), 41-46.

Sugandi, Dede; Eridiana, Wahyu; Malik, Yakub; T. Sugito, N. (2009). Sosialisasi dan pelatihan pemanfaatan biogas skala rumah tangga sebagai sumber energi alternatif ramah lingkungan di kampung parabon desa warnasari kecamatan pengalengan kabupaten bandung. Ks I, 17.

Sunyoto, Danang Dwi Saputro, S. (2016). Pengolahan Sampah Organik Menggunakan Reaktor Biogas Di Kabupaten Kendal. Rekayasa, 14(1), 2936.

https://doi.org/10.15294/rekayasa.v14i1.7 721 